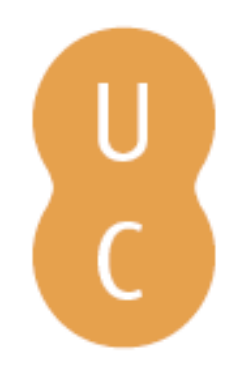

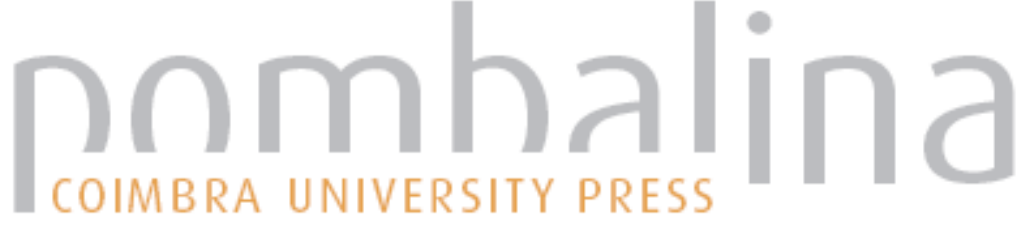

\section{Alta velocidade: as estratégias de implementação e os efeitos da estação}

Autor(es): $\quad$ Galiau, Sónia; Sousa, João Figueira de

Publicado por: Imprensa da Universidade de Coimbra

URL

persistente:

URI:http://hdl.handle.net/10316.2/30849

DOI:

DOI:http://dx.doi.org/10.14195/978-989-26-0244-8_56

Accessed : $\quad$ 26-Apr-2023 09:36:10

A navegação consulta e descarregamento dos títulos inseridos nas Bibliotecas Digitais UC Digitalis, UC Pombalina e UC Impactum, pressupõem a aceitação plena e sem reservas dos Termos e Condições de Uso destas Bibliotecas Digitais, disponíveis em https://digitalis.uc.pt/pt-pt/termos.

Conforme exposto nos referidos Termos e Condições de Uso, o descarregamento de títulos de acesso restrito requer uma licença válida de autorização devendo o utilizador aceder ao(s) documento(s) a partir de um endereço de IP da instituição detentora da supramencionada licença.

Ao utilizador é apenas permitido o descarregamento para uso pessoal, pelo que o emprego do(s) título(s) descarregado(s) para outro fim, designadamente comercial, carece de autorização do respetivo autor ou editor da obra.

Na medida em que todas as obras da UC Digitalis se encontram protegidas pelo Código do Direito de Autor e Direitos Conexos e demais legislação aplicável, toda a cópia, parcial ou total, deste documento, nos casos em que é legalmente admitida, deverá conter ou fazer-se acompanhar por este aviso. 


\section{TRUNFOS DE UMA}

\section{EOGRAFIA ACIVA}

\section{DESENVOLVIMENTO LOCAL,}

AMBIENTE,

ORDENAMENTO

E TECNOLOGIA

Norberto Santos

Lúcio Cunha

COORDENAÇÃO 
Sónia Galiau, João Figueira de Sousa

e-GEO - Centro de Estudos de Geografia e Planeamento Regional. Faculdade de Ciências Sociais

e Humanas. Universidade Nova de Lisboa

\author{
ALTA VELOCIDADE: \\ AS ESTRATÉGIAS DE IMPLEMENTAÇÃO E OS EFEITOS DA ESTAÇÃO
}

\title{
1. ENQUADRAMENTO
}

A evolução do sector dos transportes é marcadamente distinta para os vários modos de transporte, influenciada por um conjunto complexo de factores económicos, políticos, sociais, e pelas constantes inovaçôes tecnológicas. Neste contexto, o caminho-de-ferro teve o seu apogeu no século XIX, considerado como modo de transporte e símbolo da Revoluçâo Industrial. Posteriormente, perante os novos padrôes de mobilidade e as vantagens competitivas do sector rodoviário, a ferrovia inverteu o seu crescimento com a desactivação de inúmeras linhas e serviços. Os problemas inerentes ao crescimento rodoviário, levaram, recentemente, a recentrar políticas de utilização do caminho-de-ferro, uma aposta na intermodalidade, que passa pela dinamização/renascimento do sector e pela reestruturação de serviços competitivos. Os projectos de alta velocidade integrados nas políticas comunitárias são como uma alavanca para a modernização do sector. No entanto, é fundamental, a articulação entre os comboios de alta velocidade e os comboios convencionais, o serviço que estabelecem e as próprias infra-estruturas, as novas e as herdadas do século passado. No fundo, o desafio é conjugar as suas características e diferenças, no sentido de complementarem-se entre si.

\section{Comboios de Alta Velocidade Versus Comboios Convencionais}

A complexidade do tema e a controvérsia gerada, nomeadamente, na esfera política e económica, incentivada pelos meios de comunicação social, leva-nos, primeiramente à definição do conceito. Segundo a International Union Railways (UIC), não há uma definição única de alta velocidade, variando consoante o país entre as velocidades: 200/220 Km/h e $300 \mathrm{Km} / \mathrm{h}$. A UIC indica que o serviço de alta velocidade é composto por várias componentes e que sáo estas que ditam a característica de alta velocidade, assim um comboio que atinja pelo menos $250 \mathrm{Km} / \mathrm{h}$ é considerado de alta velocidade. Os comboios que apesar de não atingirem essa velocidade, oferecerem uma qualidade de serviço elevada podem ser considerados como tal $(200 \mathrm{Km} / \mathrm{h})$. Em alguns casos, devido a características topográficas, ou por circularem em espaço urbano, em pontes e/ou túneis, náo atingem os critérios de velocidade, no entanto, são considerados como alta velocidade. A normativa europeia 
(Directiva 2008/57/CE de 17 de Junho de 2008 relativa à interoperabilidade do sistema de transeuropeu de alta velocidade) define as características da alta velocidade e segue na íntegra os critérios da associação internacional. Assim, é na franja entre os 200-250 Km/h que se estabelece a fronteira entre as linhas convencionais e as de alta velocidade.

Existem vários tipos de exploraçáo em alta velocidade, por exemplo, o uso exclusivo de linhas de alta velocidade tem um custo económico muito elevado, que serve somente grandes áreas densamente populosas, como acontece no Japão. Na França, os comboios de alta velocidade podem circular em linhas convencionais, no entanto, estes não circulam nas linhas de alta velocidade. A Alemanha e a Itália têm um sistema misto, o que permite a circulaçáo de comboios de alta velocidade e convencionais em ambas as linhas. A futura rede de alta velocidade portuguesa, segue o sistema de exploraçáo da Espanha, em que os comboios convencionais conseguem circular nas linhas de alta velocidade, mas o contrário não é possível.

Os efeitos no território do comboio de alta velocidade distanciam-se dos efeitos que são preconizados pelos comboios convencionais, para se aproximarem dos efeitos dos aeroportos, produzindo no espaço ilhas de máxima acessibilidade em torno das estaçóes de alta velocidade, ignorando os espaços intermédios, sem conexáo com a rede. O comboio de alta velocidade produz assim alguns dos efeitos do aviáo, ao conectar algumas cidades, mantendo uma distância entre estaçóes superior ao comboio convencional, mas inferior aos aeroportos.

Desta forma, é necessário compensar os efeitos polarizadores através da interconexão das infra-estruturas, repartindo homogeneamente os benefícios da alta velocidade por todo o território (Puebla, 1998). A União Europeia alerta também para esse mesmo efeito:

"Deverá ser necessário para as infra-estruturas de grandes prestaçôes, como a alta velocidade e as auto-estradas, não absorver os recursos das regióes menos favorecidas e periféricas, assim como evitar que as ditas infra-estruturas atravessem estas regióes sem as conectar (efeito túnel). A politica de desenvolvimento territorial deveria também ser completada por uma rede secundária."

(Comissão Europeia, 1998, citada em Puebla, 1998)

\section{Projectos Europeus de Alta Velocidade: Itália, Alemanha, FrançA e Espanha}

O desenvolvimento das redes de alta velocidade é relativamente recente, à excepção do Japão, França e Itália, todos os outros países concretizaram os seus projectos nas últimas décadas (1990 e 2000). O velho continente Europeu destaca-se pela concentração da maior parte da extensão da rede (total de $9919 \mathrm{Km}$ ), com cerca de $5598 \mathrm{Km}$, valor que corresponde a $56 \%$ da rede total do Mundo ${ }^{1}$.

Em 1994, na Cimeira Europeia de Essen, foram definidos os projectos prioritários transeuropeus, os quais têm como objectivo: a construção, modernização e inter-conexão das principais infra-estruturas, tendo em vista o desenvolvimento do mercado único, reforçando a competitividade económica e a coesão no espaço europeu (MOPTC, 2006: 61-62). Posteriormente, a Decisão n. ${ }^{o}$ 884/2004/CE de 29 de Abril define 30 projectos

\footnotetext{
${ }^{1}$ Segundo a UIC, a rede encontra-se em constante crescimento no Mundo e tem inúmeros projectos que estão a ser construídos (8 $295 \mathrm{Km})$ ou a ser planeados $(18753 \mathrm{Km})$.
} 
prioritários (18 são para o transporte ferroviário), tendo em conta o alargamento da $\mathrm{UE}^{2}$. Actualmente, estáo concretizados os corredores que ligam a França ao Reino Unido, à Bélgica, e à Alemanha, existindo perspectiva de ligação a Itália, a Espanha e à Suiça.

Figura 1 - Rede de Alta Velocidade Europeia

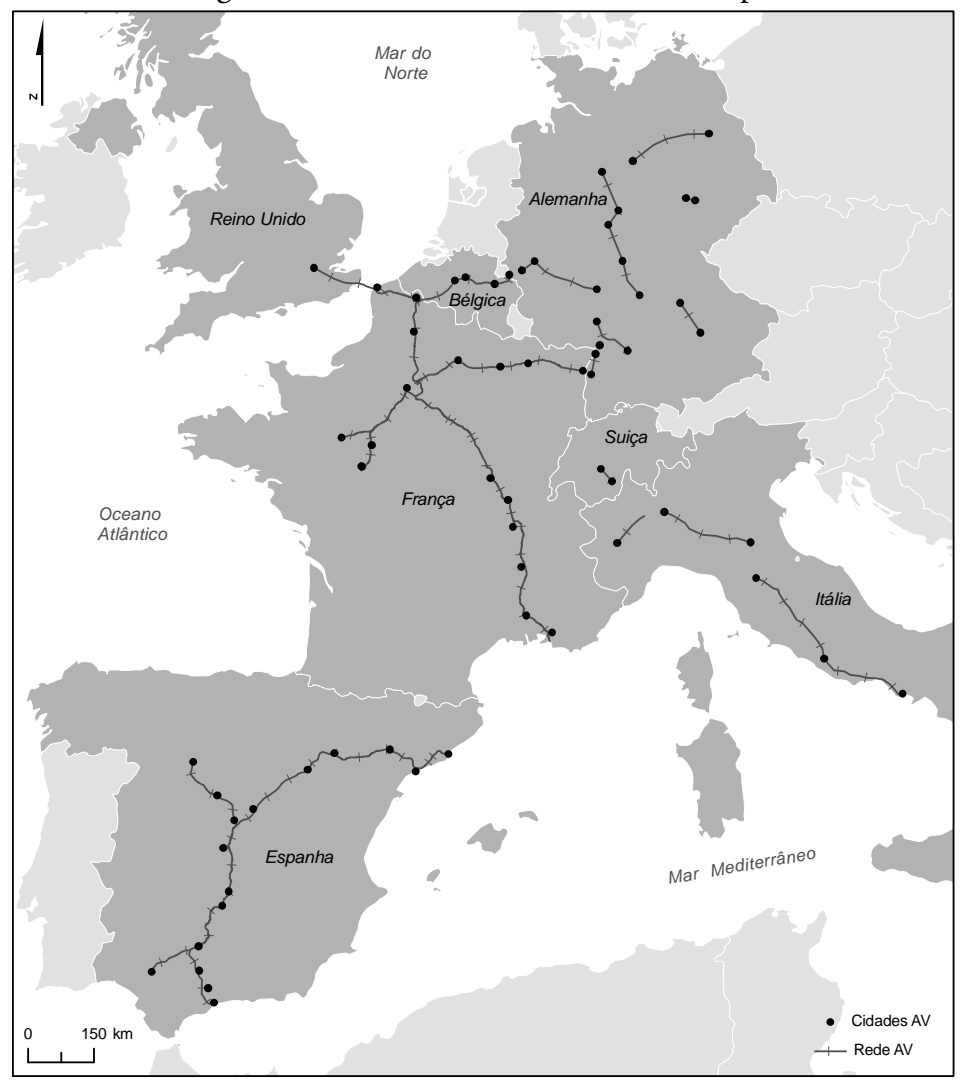

Anteriormente à definição de políticas europeias, os países começaram a desenvolver a sua própria rede, com especificidades e princípios diferentes (Figura 1). A Alemanha desenvolveu um sistema misto de tráfego com múltiplos nós de ligação, devido à estrutura do seu povoamento, disseminado por todo o território. As estaçôes de alta velocidade são muitas vezes reaproveitadas das herdadas do século XIX, existindo, uma concertação entre a companhia ferroviária e os diferentes municípios, o que favorece a elaboração de planos especiais em torno das estaçóes, os quais definem os usos do solo e a conexão com a rede de transporte. A estação é ponto de referência na cidade, nó de atraç̧ão e ligação entre os vários modos de transporte, facto que contribui para o uso intensivo do sistema de trans-

\footnotetext{
${ }^{2} \mathrm{O}$ investimento previsto é de cerca de 340 mil milhóes de euros, dos quais 88.5 foram implementados até ao fim de 2004, enquanto que entre 2005-2020 prevê-se um investimento de cerca de 252 mil milhóes de euros (Comissão Europeia, 2005), concentrado nos modos ferroviário, marítimo e fluvial.
} 
porte. À semelhança da Alemanha, a rede italiana ${ }^{3}$ aposta na regeneração das estaçôes já existentes, mantendo o serviço nas mesmas cidades, mas com uma qualidade superior.

Contrariamente, o modelo centralizado adoptado pela França, tinha como principal objectivo ligar as cidades mais populosas no menor tempo possível, em detrimento dos espaços intermédios ${ }^{4}$. Posteriormente, o modelo foi abandonado, apostando numa lógica em que cidades médias e de pequena dimensão poderiam ter estação, com algumas condicionantes, nomeadamente no tipo de serviço e na localização da infra-estrutura. Algumas dessas estaçôes são conhecidas por estaçôes do deserto ou estaçóes perdidas (Mannone, 2005:22), por se localizarem fora do núcleo urbano e sem interconexão com outros modos de transporte. A rede espanhola de alta velocidade segue o esquema radial definido pela França, embora com algumas especificidades, designadamente, no que se refere ao tipo de serviço (existe uma segregação de tráfego, com tarifas especiais para absorver o maior número de passageiros, serviço inicialmente implementado no corredor entre Madrid-Puertollano-Cidade Real, adjudicado mais tarde a outros corredores).

\section{CidAdes de Alta VElocidade EM FranÇA E EsPanHa: ESTRATÉGIAS E EFEITOS DA ESTAÇÃO}

Os efeitos da estação estão relacionados com a proximidade a grandes áreas metropolitanas, uma vez que os efeitos gerados são distintos no caso da cidade estar, em relação a uma metrópole, a uma distância possível de transpor diariamente, proporcionando um aumento de movimentos pendulares. Neste sentido, existem dois tipos de distância passíveis de analisar:

- Cidades a menos de $100 \mathrm{Km}$ (30 minutos): unem-se de forma descontínua, convertendo-se possivelmente, em sub-centros especializados;

- Cidades a mais de uma hora de uma área metropolitana vêem aumentar parcialmente os seus processos metropolitanos. Este fenómeno deve-se a três aspectos essenciais (Menéndez, Coronado e Rivas, 2002, citado em Francês, 2005:45): o tempo de viagem que potencia os movimentos de residência-trabalho a grandes distâncias; o número de paragens, em que na primeira paragem há um maior número de passageiros pendulares, e a frequência do serviço, que condicionam as oportunidades de deslocamento a diversas horas.

O aparecimento de novos fenómenos espaciais, como as migraçóes pendulares a grande distância, parece evidenciar a emergência de um novo conceito de área metropolitana, o qual apresenta um configuração não contínua, com o núcleo central a posicionar-se a quase 200 Km de distância de novas frentes de crescimento urbano (Tão, 2009:17).

A localização da estação influencia também os efeitos produzidos no espaço. Esta assume-se como um elemento estruturante e simbólico na vida urbana, onde se condensa e interagem uma pluralidade de funçôes, constituindo-se, por isso, como um pólo urbano vital, onde operam incessantes movimentos de pessoas e bens.

Os diferentes tipos de localização da estação estão representados na figura 2.

\footnotetext{
${ }^{3} \mathrm{O}$ projecto desenvolvido tinha como objectivo criar alternativas de transporte no corredor Norte-Sul que estava saturado (Roma-Florença, 1981) coincidindo na mesma linha os serviços de passageiros e mercadorias.

${ }^{4}$ A primeira ligação entrou em funcionamento em 1982 e veio dar resposta ao intenso tráfego que existia entre Paris-Lyon.
} 
Figura 2 - Localizações possíveis das estaçôes de alta velocidade, relativamente ao núcleo urbano
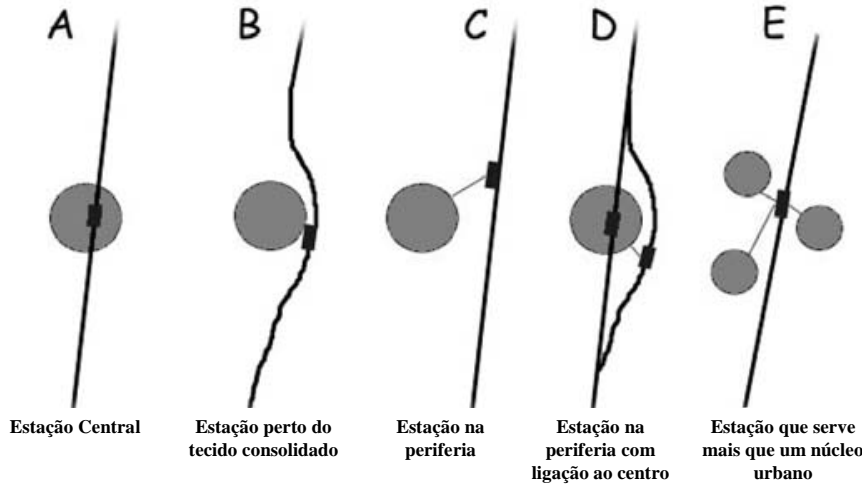

Fonte: Batalla, Abad e Lázaro (2001:5).

No que diz respeito à localização no centro (localização A) esta facilita a sua interligação com outros modos de transporte, podendo também permitir uma eventual reconversão de uma parte antiga da cidade; no entanto, tem inconvenientes marcados pela falta de espaço na sua envolvente, pelo efeito barreira (proporcionando a divisão de "duas" cidades), e por condicionar a velocidade comercial dos comboios que não têm paragem nessa estação. A localização B náo tem os mesmos inconvenientes previstos anteriormente, existindo apenas algumas restriçóes de espaço, no entanto a sua proximidade ao centro possibilita as deslocaçóes a pé. A localização C compreende outro tipo de limitaçóes, nomeadamente, no que se refere à ligaçáo ao centro da cidade, potenciando, à partida, o uso do veículo privado na ausência de alternativas viáveis. Esta localização potencia áreas de expansão, nas quais se desenvolvem diversas actividades económicas. A localização D junta as características da estação A e C. A localização E serve um conjunto de aglomerados, esquema que apenas foi implementado na França. Existe ainda uma variante da localização A, em que a cidade é servida por um estação central, no caso de ter paragem, e por um corredor by pass, destinado aos comboios que náo têm paragem na cidade, permitindo que a ligação entre as outras cidades não tenha qualquer tipo de condicionante a nível de tempo (cidade de Lérida no corredor Madrid-Barcelona).

Da análise das cidades com estação de alta velocidade em França e em Espanha (Figura 3), verificamos uma tendência para a localização da estaçáo no centro de cidades com alguma dimensão, aproveitando o traçado do século XIX, permitindo a regeneração de núcleos históricos (Córdova, Valladolid, Le Mans, Lille, Madrid, Barcelona, Paris e Lyon). As cidades pequenas e de média dimensão são consideradas como paragens intermédias entre grandes metrópoles. Estas cidades são, porventura, as que têm maior possibilidade de escolha na localização da estação, registando-se casos para quase todo o tipo de localização. No entanto, há uma clara predominância pela localização $\mathrm{C}$ (fora do núcleo urbano) principalmente em França (Mâcon, Avignon e Valence). Existem algumas soluçóes inovadoras, nomeadamente em cidades de pequena dimensão (Vendône com cerca de 18000 habitantes), localizando a estação na periferia. Há casos em que a estação serve: vários aglomerados urbanos (estação de Le Creusot, que no total serve 102000 habitantes e está localizada a $4 \mathrm{~km}$ de Montchanin (6 000 habitantes) e a $40 \mathrm{~km}$ de Châlon (50 000 habitantes); ou uma região com elevada densidade populacional (estação de Haute Picardie que serve 300000 habitantes e está a 40 $\mathrm{km}$ de duas localidades mais importantes da regiáo). 
Figura 3 - Cidades de Alta Velocidade-Casos de Estudo, quanto à localização da estaçáo e à dimensão populacional

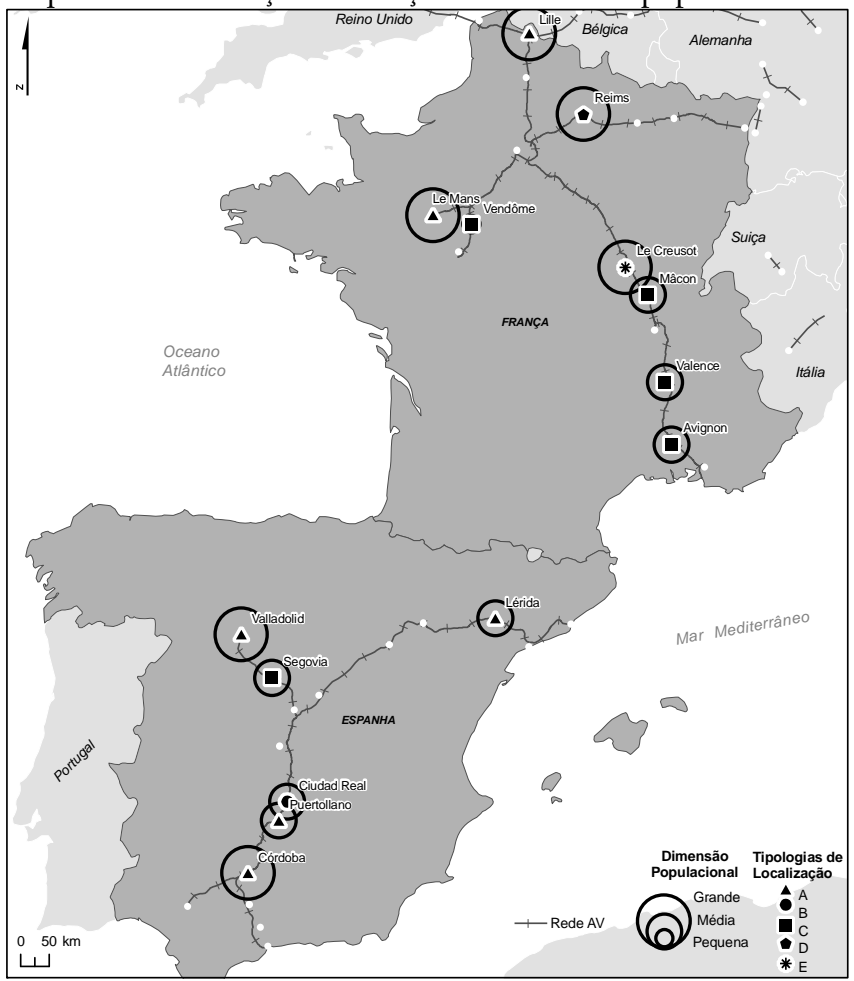

\section{CONCLUSÃO}

Os efeitos transversais preconizados, com maior ou menor incidência, dependendo da localização da estação de alta velocidade, indicam que esta promove uma transformação urbanística do espaço envolvente, reorganiza centros históricos ou fomenta novas centralidades, associando outros projectos (parques tecnológicos). Os efeitos temporários imediatos registam-se no sector da construção, com ganhos significativos nos postos de trabalho e também no arrendamento imobiliário. O sector do turismo sofre, numa primeira instância, uma diminuição do número de turistas por motivos profissionais, uma vez que deixam de ter necessidade de pernoitar na cidade. No sector da indústria, salvo as cidades que têm um tecido económico assente neste sector, os efeitos da estação são bastante ténues, apesar da promoção de espaços a custos controlados, poucas são as empresas que consideram a alta velocidade como elemento decisor da sua localização. A transformação mais marcante resulta do aumento dos movimentos pendulares a grandes distâncias, considerando que a melhoria da acessibilidade é superior do que na periferia de grandes áreas metropolitanas, onde, por sua vez, existe uma melhor qualidade de vida. A populaçáo, nomeadamente profissionais qualificados e superiores, tende a deslocar-se para trabalhar na grande metrópole e manter a residência na cidade mais pequena. Considerando os efeitos temporários de crescimento de postos de trabalho e os efeitos permanentes dos movimentos pendulares, existe associado a estes factores, um crescimento populacional efectivo. 
No que se refere às políticas adoptadas para a implementação da estação de alta velocidade na cidade, há uma preocupação inicial de reserva de solo na envolvente à estação (medidas de previsão). A integração da estação nas políticas de desenvolvimento local está prevista somente em Segóvia e Mâcon, em que há uma clara intenção de estender o núcleo actual ao novo centro polarizado pela estação. As medidas de gestáo que dizem respeito à coordenação intermodal não são fomentadas, principalmente nas estaçóes da periferia, em que apesar de inicialmente terem desenvolvido serviços de ligação ao centro através de autocarros, estes foram suprimidos por falta de passageiros, fazendo com que a estaçáo fique isolada de outros modos de transporte (Universidades de la Red de Cuadernos de Investigación Urbanística, 2005).

Existe uma ausência de planificação global cuja origem está, em parte, na falta de concertação entre instituiçóes sectoriais e locais. Esta planificação é dominada pela iniciativa privada, vinculada a interesses imobiliários de promoção residencial. Relativamente às expectativas, por exemplo, no caso das gares bis (Mâcon, Vendôme, Le Creusot) (Thompson, 1998), a estação de alta velocidade foi encarada como impulsionadora da economia local, e foram desenvolvidos projectos que não estão enquadrados na dinâmica local.

A evolução das cidades com estação de alta velocidade, os princípios, as estratégias, as perspectivas iniciais e os efeitos reais produzidos permitem definir e reiterar experiências que deverão ser tidos em conta nas futuras cidades AV.

\section{REFERÊNCIAS BIBLIOGRÁFICAS}

Batalla, C., Abad, B., Lázaro, J. 2001, Alta Velocidad Ferroviaria en Ciudades Pequeñas Europeas: Nuevas Oportunidades para el desarrollo urbano.

Comissão Europeia. 2005, 'Study on Strategic Evaluation on Transport Investment Priorities under Structural and Cohesion funs for the Programming Period 2007-2013’ Disponível em: http://ec.europa.eu/regional_policy/ /sources/docgener/evaluation/pdf/evasltrat_tran/greece.pdf

Community of European Railway and Infrastructure Companies. 2009, Railways and the Environment. Building on the railways' Environmental Strengths. Brussels.

Directorate-General for Energy and Transport - European Commission. 2009, European High Seep Rail-An easy way to connect. Étude sur l'état de développement et les perspectives d'avenir du réseau transeuropéen de chemin de fer à grande vitesse. Rapport (Version Finale). Bruxelas.

Francês, J. 2005, Situaciones y retos territoriales de la alta velocidad ferroviária en ciudades pequeñas en España, I Congreso Nacional de la Red de Ciudades AVE. El tren de Alta Velocidad Española: Análisis, Evaluación y perspectiva Futura. Guadalajara, pp.42-51.

Mannone, V. 2005, 'La nodalité des gares TGV périphériques', Les cahiers scientifiques du transport n. ${ }^{4} 48: 45-58$, [Online] Disponível em: http:// afitl.ish-lyon.cnrs.fr/CST/precedents-numeros/N48/Facch48.pdf

MOPTC, Ministério das Obras Públicas, Transportes e Comunicações 2006, Orientaçôes Estratégicas para o Sector Ferroviário. Disponível em: http://www.moptc.pt/cs2.asp?idcat=1051

Puebla, J. 1998, 'Redes, espacio y tiempo', Anales de Geografia de la Universidad Complutense, 1998, n. ${ }^{\circ} 18:$ 6586, [Online] Disponível em: http://revistas.ucm.es/ghi/02119803/articulos/AGUC9898110065A.PDF

Tão, M. 2009, 'A rede de Alta Velocidade ferroviária e o seu impacto em Évora, um quadro prospectivo', $2^{\circ}$ Workshop APDR - Associação para o Desenvolvimento Regional-Cenários de Transformação da paisagem face aos factores de mudança globais (actas não publicadas), Évora.

Thompson, I. 1998, 'The production of urban space by the train à grande vitesse: three case studies of Gare-bis', Modern \& Contemporary France, 6(1):21-32. [Online] Disponível em: http://pdfserve.informaworld. com/683425_778384746_79266 3760.pdf

Universidades de la Red de Cuadernos de Investigación Urbanística 2005, 'Alta Velocidad ferroviaria y ciudad: estrategias de incorporación de las nuevas estaciones periféricas francesas y españolas', Ci[ur] 44 . 